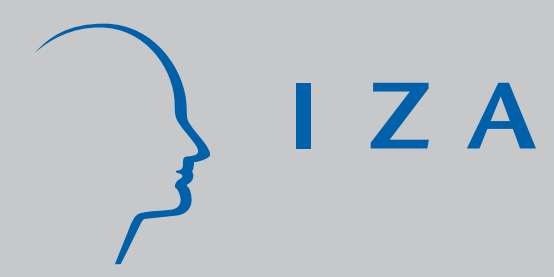

IZA DP No. 183

Aggregate-Level Migration Studies as a Tool for Forecasting Future Migration Streams

Michael Fertig

Christoph M. Schmidt

August 2000 


\title{
Aggregate-Level Migration Studies as a Tool for Forecasting Future Migration Streams
}

\author{
Michael Fertig \\ University of Heidelberg \\ Christoph M. Schmidt \\ University of Heidelberg, CEPR, London and IZA, Bonn \\ Discussion Paper No. 183 \\ August 2000 \\ IZA \\ P.O. Box 7240 \\ D-53072 Bonn \\ Germany \\ Tel.: +49-228-3894-0 \\ Fax: +49-228-3894-210 \\ Email: iza@iza.org
}

This Discussion Paper is issued within the framework of IZA's research area Mobility and Flexibility of Labor Markets. Any opinions expressed here are those of the author(s) and not those of the institute. Research disseminated by IZA may include views on policy, but the institute itself takes no institutional policy positions.

The Institute for the Study of Labor (IZA) in Bonn is a local and virtual international research center and a place of communication between science, politics and business. IZA is an independent, nonprofit limited liability company (Gesellschaft mit beschränkter Haftung) supported by the Deutsche Post AG. The center is associated with the University of Bonn and offers a stimulating research environment through its research networks, research support, and visitors and doctoral programs. IZA engages in (i) original and internationally competitive research in all fields of labor economics, (ii) development of policy concepts, and (iii) dissemination of research results and concepts to the interested public. The current research program deals with (1) mobility and flexibility of labor markets, (2) internationalization of labor markets and European integration, (3) the welfare state and labor markets, (4) labor markets in transition, (5) the future of work, (6) project evaluation and (7) general labor economics.

IZA Discussion Papers often represent preliminary work and are circulated to encourage discussion. Citation of such a paper should account for its provisional character. 
IZA Discussion Paper No. 183

August 2000

\section{ABSTRACT \\ Aggregate-Level Migration Studies as a Tool for Forecasting Future Migration Streams*}

Assessing the migration potential and predicting future migration streams are among the most relevant, yet least well understood topics of migration research. The usual approach taken to address aggregate-level prediction problems is to fit ad hoc specifications to historical data, and to extrapolate from these estimates on the basis of conditioning information that is assumed to be known with certainty. In this context, this strategy faces formidable problems that exceed the usual difficulties arising for the prediction of economic variables. This paper addresses this extrapolation problem formally, with an application to the case of EU-enlargement and the ensuing migration streams to be expected from Eastern Europe.

JEL Classification: J11, J61, C23.

Keywords: Demographic Structure, Variance Components, GMM

Christoph M. Schmidt

Department of Economics (Econometrics)

University of Heidelberg

Grabengasse 14

69177 Heidelberg

Germany

Tel.: +49-6221-54 2955

Fax: +496221543640

Email: Schmidt@uni-hd.de

\footnotetext{
* We are grateful for helpful comments by David Card, Slobodan Djajic and participants of the esfconference "Migration \& Development" and to Katharina Türpitz for research assistance.
} 


\section{Non-Technical Summary}

From the vantage point of economic policy, assessing migration potential and predicting future migration streams are among the most relevant, yet least well understood topics of migration research. Most theoretical models and a large range of econometric studies successfully address heterogeneity at the individual level. In the aggregate, though, many important explanatory factors are shared within the regions of origin and destination, rendering the individual-level results inappropriate as a predictive tool, and necessitating an analysis over time and space. The usual approach taken to address aggregate-level prediction problems is to fit ad hoc specifications to historical data, and to extrapolate from these estimates on the basis of conditioning information that is assumed to be known with certainty.

This strategy faces formidable problems that exceed the usual difficulties in predicting economic variables. One reason for these deficiencies is the paucity of the data material, making precise estimation of historical relationships both between demographic and economic determinants and the resulting migration streams, and the univariate prediction of those economic variables very difficult. Typically, forecasts in the literature do not address this problem of precision systematically. The second, and conceptually more severe problem is the identification problem that has to be solved satisfactorily for any valid extrapolation, irrespective of the available data points. In the particular case at hand, it is not only the usual temporal invariance that would have to be imposed but also the additional invariance across space: often future migration is likely to take place between origin and destination regions that do not share a common history of migration. The convincing choice of the country-specific intercept for countries for which no previous migration record exists is therefore the principal conceptual challenge for the prediction - yet, this has not been adressed formally in any of the previous papers on this topic.

This paper formally addresses this double extrapolation problem, with an application to the case of EU enlargement and the ensuing expected migration streams from Eastern Europe after the associated changes in the regulations concerning migration. The paper thus intends to contribute to the clarification of three important issues: 
1. Specific identification assumptions have to be invoked by every aggregate migration study.

2. The role of demographic factors in the migration decision is widely neglected; evaluating the size and impact of migration flows has to take into account this major supply side factor.

3. Imposing more and more structure on the estimation of the determinants of aggregate migration flows typically reduces uncertainty within sample but may not necessarily lead to better forecasts.

In developing our own approach to the problem, we depart from the received migration literature - whose emphasis is typically on the explanation of migration activity, not its prediction into the future - and pursue a very parsimonious specification of migration rates that is fitted to historical data on the German post-WW II immigration experience. Its formulation explicitly allows for persistent economic and non-economic differences to be captured by a set of country-specific random effects which, together with a time-specific and a white noise component drive the fluctuation of migration rates around its average across time and space. The relative magnitudes of these unobserved orthogonal variance components lends itself naturally to a discussion of the prediction problem raised by EU enlargement.

Specifically, if the new EU members were to display the emigration behavior to Germany that has characterized the typical origin country during the (high-immigration) post-WW II era, prospective net immigration would be of almost negligible magnitude. If, by contrast, they were to display a substantially more pronounced emigration propensity, future net immigration could be much larger, albeit still relatively moderate when considering the figures circulating in the public debate on this issue. 


\section{Introduction}

From the vantage point of economic policy, assessing migration potential and predicting future migration streams are among the most relevant, yet least well understood topics of migration research. Most theoretical models and a large range of econometric studies successfully address heterogeneity at the individual level, with an emphasis on the detection of demographic and socio-economic determinants of the individal migration decision, or on the identification of the appropriate decision unit. In the aggregate, though, many important explanatory factors are shared within the regions of origin and destination, rendering the individual-level results inappropriate as a predictive tool, and necessitating an analysis over time and space. The usual approach taken to address aggregate-level prediction problems is to fit ad hoc specifications to historical data, and to extrapolate from these estimates on the basis of conditioning information that is assumed to be known with certainty $^{1}$.

This strategy faces formidable problems that exceed the usual difficulties in predicting economic variables. One reason for these deficiencies is the paucity of the data material, making precise estimation of historical relationships both between demographic and economic determinants and the resulting migration streams, and the univariate prediction of those economic variables very difficult. This concern is already relevant for demographic variables, although one might reasonably well predict future population size and age structure. It applies even more to the prediction of economic developments, such as changes in wages, income and employment. Typically, forecasts in the literature do not address this problem of precision systematically.

The second, and conceptually more severe problem is the identification problem that has to be solved satisfactorily for any valid extrapolation, irrespective of the available data points. In the particular case at hand, it is not only the usual temporal invariance that would have to be imposed directly or via the parameterization of trends in variables or relationships, but also the additional invariance across space: often future migration is likely to take place between origin and destination regions that do not share a common history of migration. Moreover, the intertemporal pattern of regulations and institutions relevant for migration streams, albeit endogenous to social and 
economic changes, is often taken as exogenously given.

This paper will formally address this double extrapolation problem, with an application to the case of EU enlargement and the ensuing expected migration streams from Eastern Europe after the associated changes in the regulations concerning migration. The paper thus intends to contribute to the clarification of three important issues:

1. Specific identification assumptions have to be invoked by every aggregate migration study. These assumptions might appear particularly restrictive in studies being motivated by microeconomic considerations; basing the analysis on theoretical reasoning is necessary, though, if we want to improve upon mechanical curve fitting.

2. The role of demographic factors in the migration decision is widely neglected; evaluating the size and impact of migration flows has to take into account this major supply side factor. This holds particularly within the EU which erects fairly low institutional barriers to migratory movements of their own citizens.

3. Imposing more and more structure on the estimation of the determinants of aggregate migration flows has important consequences for the forecasting of future migration flows; more structure typically reduces uncertainty within sample if the invoked assumptions are correct, but may not necessarily lead to better forecasts.

The paper is structured into two major parts. Section 2 provides a selective survey of existing aggregate-level migration studies. The first half of this section is devoted to technical issues, emphasizing the characterization of the particular empirical strategy chosen in each paper to identify the impact of explanatory demographic and economic factors on the magnitude of migration flows. Here we aim at clarifying the implicit and explicit identification and invariance assumptions invoked by the migration literature. In this context, the role of structural economic models as opposed to reducedform models as predictive tools is also discussed. Recent developments link the migration literature to the macro-economic literature on convergence by introducing political variables such as freedom and rule-of-law indices; the predictive potential and the additional problems arising from such variables 
are explored. The second half of section 2 provides a synoptic discussion of the results of existing studies of aggregate migration flows to Germany, in the light of these technical arguments; specific emphasis is on the explanation of agreement and disagreement between existing studies as results of the chosen identification strategies.

The second part of the paper will develop our own approach to the particular problem of predicting future migration streams from Central and Eastern Europe to the West within a unified Europe. This topic has received increased attention in recent years, with the answers varying substantially across studies (cf. e.g. BAUER AND ZimmERMAnN (1999), FERTig (1999) and Sinn (1999), (2000)). In section 3, we prepare this empirical application by formulating a generic theoretical model as a frame of reference, and then discussing alternative identification assumptions. On the basis of our Western data for the post-WW II period, we proceed in section 4 to estimate the historical relationship between migration to Germany and its aggregate-level determinants. We then use these estimates to generate concrete predictions of the immigration flows from Eastern Europe following EU

enlargement, with a focus on the impact of varying identification strategies on these results.

In section 5, we summarize our results, both on the methodological lessons to be drawn and the concrete results of our empirical application, and provide an agenda for further research on this issue.

\section{The State of Discussion}

In this section, we will provide a selective survey of existing aggregate-level studies of international migration. Our review emphasizes the particular empirical strategy chosen by each paper to identify the impact of explanatory demographic and economic factors on the magnitude of migration flows. The aim of this focus is the clarification of the implicit and explicit identification and invariance assumptions invoked by the migration literature. In this context, the role of structural economic models as opposed to reduced-form models as predictive tools will also be discussed. 


\subsection{Empirical Strategies and Identification Assumptions}

Empirical analyses of international migration typically rests on aggregate data. In the particular case of (gross or net) emigration from a set of origin countries to a single destination these models take the generic form:

$$
m_{s, t}=\mu_{s}+X_{s, t} \beta_{s}+\delta m_{s, t-1}+\epsilon_{s, t}
$$

where $m_{s, t}$ typically denotes an appropriate measure of the aggregate migration rate (i.e. the actual migration as a proportion of potential migrants at the origin) from sending country $s$ in year $t$. The parameter $\mu_{s}$ captures all unobservable aspects of the process which are specific to country $s$ but constant over time, while the k-dimensional matrix $X_{s, t}$ denotes the observable time-varying characteristics of country $s$ at time $t$ (relative to the destination), and $\beta_{s}$ and $\delta$ are (vectors of) unknown parameters to be estimated. Since the lagged dependent variable introduces dynamics into expression (1), $\delta<1$ is a necessary condition for the stationarity of the process. Finally, $\epsilon_{s, t}$ is the error term reflecting all unsystematic influences on the process.

Variations of this generic form are typically more restrictive, either by expressing country-specific intercepts as a linear combination of time-constant observable characteristics, by restricting slope coefficients to be equal across countries, $\beta_{s}=\beta \forall s$, by omitting the lagged dependent variable, or by a combination of these restrictions. Usually, this model specification and the concrete choice of explanatory factors included in $X$ is more or less based on microeconomic considerations relating the individual decision to migrate or not to rational economic behavior in the context of utility or income maximization.

Building on a long-standing tradition of economic reasoning about the determinants of migration, at the center of attention in such models are usually the economic variables collected in $X$. When social scientists first started thinking about the determinants of aggregate migration flows (a prominent early contribution is RAVENSTEIN (1889)), they did this in the demographically relatively homogenous context of internal migration. The large variety of possible driving forces offered by these contributions is a tribute to the ingenuity of the social sciences in modeling human motivation and behavior.

Current studies typically follow the seminal paper by SJASTAAD (1962) and 
understand migration as an investment in human capital. This approach assumes that in their individual decision agents weigh current cost of migration, direct as well as opportunity cost, against the stream of benefits to be expected after the move, most prominently increased wages.

Yet, both historical data as well as current accounts of the problem (see for instance Plakans And Wetherell (1995) and Rogers and Castro (1986)) demonstrate clearly that migration typically happens in a narrow band of the life cycle, ranging from early adulthood to, at most, the prime of the working career. Since the demographic structure usually varies much more across countries than within regions of the same country - as a manifestation of differences in fertility, mortality, and migration ${ }^{2}$ - one would certainly expect deviations in this structure to be prime determinants of migration flows. Specifically, the first question should be about the size of the population in the core migration age band - after all, it is not the individual migration decision that an aggregate study wants to explain, but the convolution of individual decisions, motivated economically or otherwise, with demographic structure.

Thus, in the context of international migration it seems rather unfortunate that current analysts often think first and foremost about the economic differences when they attempt to assess migration potential (see for instance SinN (1999)). Conceptually, it is the very idea of migration as an investment in human capital that makes the ample supply of core age individuals in the population of the origin countries a necessary prerequisite for economic discrepancies to have an effect on migration flows. Even in the presence of substantial disadvantages in the standard of living, compared with the destination countries, will it be very unlikely that a demographically mature society would produce substantial emigration flows.

In consequence, we would expect a complex interaction of indicators of demographic structure with economic variables to yield superior explanatory power for understanding emigration activity. That is, demographic characteristics such as the fraction of core age individuals in the sending country do not simply appear as additional regressors, since this would assume that all other regressors are taken to impact on aggregate migration rates (i.e. actual migration relative to the population at the origin, irrespective of the age composition of numerator or denominator) identically, whether the origin 
country is relatively old or relatively young. In our own empirical approach, we will deviate from the reviewed literature and move emigration rates from within the core age group into the center of attention. Specifically, we will argue that for purposes of prediction the modeling strategy of choice should be to start from a simple model of emigration rates among individuals of core age. There are good reasons to be reluctant to augmenting this model by notoriously difficult to predict economic information ${ }^{3}$.

In the received literature on international migration wages and employment or unemployment rates play a major role as regressors. Mostly, percapita incomes or the growth rate of income in sending and destination countries are taken as proxies for wages. Following SJAASTAD (1962) and HARRIS AND TODARO (1970) it is expected income which is the relevant income measure for the migration decision. Expected income is typically defined by the wage times the probability of finding a job, where these variables are approximated by per-capita income and the (un-)employment rate, respectively. In the empirical application, both variables are then typically either entered separately into the regression, or parameter restrictions are imposed a priori and, perhaps, tested statistically.

In addition, there are several other variables which are often employed in empirical studies. For example, following the literature on international trade relations, some papers set up a "gravity model" which includes the geographical distance in addition to the economic variables4. Another strand of the literature focuses on potential network effects in the migration decision proxied by the stock of migrants in the destination country (an alternative interpretation of this stock variable is given below). In addition, most empirical studies employ a set of dummy variables to capture (often quite persistent) institutional and/or legal aspects, like e.g. EU membership, a common border or language. A more recent approach focuses on supplyside non-linearities á la Kuznets and includes various measures for the level of development and the political and human rights situation, (c.f. VogLeR AND RotTe (2000)), in this equation. Alternatively, health measures or life expectancy could be included. It has to be understood, that while their inclusion is based on underlying theoretical reasoning, the way these variables enter the specification is still completely ad hoc. 
The counterfactual question implicitly asked by such a model is what would have happened to immigration flows from a specific country if one or several of the explanatory factors were different. Unfortunately, one only observes a country at any point in time with a single specific configuration of explanatory variables, making the decision to use a regression model such as (1) a method of choice. This decision is not innocuous. Any particular specification of this model necessarily invokes a set of a priori identification assumptions beyond the (log-) linearity of migration rates, enabling the analyst to construct this unobserved counterfactual situation. These identification assumptions are assumed to be true for the purposes of the analysis and their validity is not reflected in the usual measures of sampling variability (SCHMIDT (1999)). Moreover, more restrictive assumptions will generally reduce the remaining uncertainty within sample if these assumptions were correct. However, the reduction of uncertainty within sample need not necessarily be accompanied by a smaller uncertainty out-of-sample, a principle evidenced by the prominence of univariate prediction models in the analysis of financial markets.

Several different and non-exclusive identification assumptions are listed below. They concern the level of aggregation (1. and 2.), the loss of information from focusing on selected origins and destinations (3.), restrictions on the parameters (4.), and restrictions on the disturbance process (5.).

1. "Population Homogeneity": Using the aggregate migration rate requires the assumption that this rate accurately reflects the average individual probability of migration for individuals from origin country $s$. The implicit assumption of no positive or negative selection due to unobservables is particularly severe, since nearly every individual characteristic, like education, marital status etc., is unobservable on the aggregate level. If this assumption is violated, using aggregate figures like the per-capita income or unemployment rates in the explanation of the migration decision is misleading since these figures do not describe the economic opportunities of the migrants correctly.

2. "Participation Assumption": Using aggregate (un-)employment rates as proxy for individual probabilities to find a job requires the assumption that participation issues play no substantial role (DUSTMANN AND 
SCHMidT (2000)), particularly since empirical studies usually do not distinguish between male and female immigrants.

3. "Stability of Alternative Destinations": Focusing the analysis on permanent immigration from different origin countries into one destination country requires the assumption that immigration into other potential destination countries varied proportionally to observed migration flows over the considered time horizon. For instance, if a substantial increase in immigration figures to Germany from, say, Turkey is accompanied by a moderate increase in the income differential between Turkey and Germany one would conclude that this moderate increase has led to the greater inflow. But if, at the same time, economic prospects in other potential destination countries deteriorated considerably, the great increase in immigration to Germany might simply stem from a redirection of flows. This argument naturally extends to the implied stability of the political and institutional environment.

4. "No Country-Specific Effects": Using an overall constant, i.e. $\mu_{s}=\mu$ $\forall s$ instead of country-specific intercepts requires that there be no persistent country-specific determinants of aggregate migration streams ${ }^{5}$. With the inclusion of country-specific intercepts, the identification of the $\beta_{s}$ exclusively stems from the time-varying components of the $X_{s, t}$ matrix. The latter, however, are typically restricted to equality, i.e. $\beta_{s}=\beta$, if one intends to allow for country-specific intercepts.

5. "Spherical Disturbances": In the case of pooled data sets, parameter estimation by pooled OLS invokes a set of severe covariance restrictions. Specifically, this estimation procedure requires the assumptions of $h o-$ moscedasticity across regions and time, no correlation across regions, and no autocorrelation across time. For a sufficiently heterogenous sample of sending countries this seems to be very implausible. For example, if there are unobserved shocks which affect migration streams from different countries in a similar manner, observed migration figures may be correlated across groups. Also, it is quite plausible that there may be shocks which will lead to a correlation across time. Finally, the sheer difference in magnitude of inflows from different countries of origin may lead to a non-constant variance across countries.

Our selective review of studies of aggregate international migration flows will demonstrate that assumptions (1.) to (3.) are typically not questioned, 
while some studies introduce country-specific effects $\mu_{s}$ at the expense of (4.), and others model their error process more carefully in a weakening of (5.). Naturally, none of the studies works without identification restrictions.

\subsection{Results of Existing Studies}

This section will synoptically discuss the results of selected existing studies of aggregate immigration flows to Germany in the light of these identification assumptions. Specific emphasis will be on the explanation of agreements and disagreements between existing studies as results of the chosen identification strategies.

Table 1: Existing aggregate-level studies of migration to Germany (around here)

The literature on empirical investigations of aggregate immigration flows to Germany is quite scarce. An early contribution is the analysis of migrant flows from Greece to Germany by KATSELi AND Glytsos (1986). In terms of the generic expression (1), we necessarily have $s=1$ in this paper. Overall, the employment rates in both countries are statistically significant in almost all variants of the basic specification, whereas for the most part the real income variables, the lagged dependent variable as well as the additional variables are not.

KARRAS AND CHISWICK (1999) utilize pooled cross section-time series data, that is $\beta_{s}=\beta$, to analyze aggregate migration flows to Germany for a sample of 17 countries of origin and a time period covering 1964-88. The authors perform two pooled OLS regressions of the net migration rate on different sets of explanatory variables. One regression uses a common constant, i.e. $\mu_{s}=\mu$, and another employs country-specific intercepts. The different sets of explanatory variables include the lagged migration rate, the per capita income ratio between Germany and the origin countries as well as the growth rates of per capita income and lags of these variables, a measure of average schooling in the sending country, a dummy variable for EU membership and different interaction terms of this dummy variable with all other variables. The sample was split into the two sub-periods 1964-73 and 1974-88. The fixed-effects specification was rejected; the results of the specification with a common intercept indicate no statistically significant effect of the income 
ratio and the schooling measure for the first sub-sample. The lagged net migration rate and the income growth rate in Germany were statistically significant in both sub-samples.

A similar approach is used by FerTig (1999). The author also uses a pooled cross section-time series dataset for 17 countries of origin and a period covering 1960-1994. The estimation equation specifies the first difference of the net migration rate in terms of the changes and the levels of the per capita income ratio (in PPP) between Germany and the sending countries as well as the changes and levels of the employment rates of the respective countries. In addition the stock of migrants, the lagged level of the net migration rate and two dummy variables for EU membership and the German guest worker system of the 1960's and 70's are included. The model is specified with country-specific intercepts, i.e. $\mu=\mu_{s}$ and estimated by iterative GLS.

The restrictions on the disturbance matrix are relaxed in a stepwise process leading to groupwise heteroscedastic and correlated disturbances. The estimation results suggest a statistically significant positive impact of the income differential, the employment rate in Germany and the dummy variable reflecting EU membership as well as a statistically significant negative effect of the employment rate in the sending countries and the lagged level of the migration rate on observed immigration flows. The stock of migrant measure and the dummy variable for the guest worker years were statistically insignificant. The author also performed forecasting scenarios for future migration streams from Eastern Europe which support the view of positive albeit moderate future inflows from those countries. The predicted figures for the first-round candidates varied between 32,900 and 36,300 immigrants per year between 1995 and 2015.

On the basis of a substantially wider set of origin countries VOGLER AND RotTe (2000) address the complex set of issues associated with the relation of migration and economic development, political freedom, rule of law, and democracy. Specifically, their dataset contains immgration flows by asylum seekers for a sample of 86 Asian and African countries between 1981 and 1995 as well as indices of political participation opportunities (Freedom House Index) and political violence (Political Terror Scale) in the respective sending country. In addition, these authors try to account for changing emigration activity in the course of development, similar to the argument 
raised in FAINI AND VENTURINI (1994). The random-effects panel data estimates of VOGLER AND RoTTE (2000) suggest a positive impact of economic differences between Germany and the countries of origin which declines in magnitude over time. The results also suggest an important role for financial restrictions and migrant networks in explaining the migration decision.

Overall, these previous studies provide an interesting, albeit not completely satisfying account of aggregate migration flows to Germany during the past decades. Specifically, the most prominent factors which are accounted for, such as wages or unemployment rates, do not yield stable results. Conceptually, in our view, most problematic in the explanation of emigration flows is the omission of source country-specific heterogeneity, accounting for which requires access to panel data. That is, studies which impose a common intercept term either follow an implicit assumption that no important persistent differences in migration activity exist across source countries, or that this variation across countries is orthogonal to the other determinants included in the specification. Yet, even under this latter, quite restrictive implicit assumption, most studies tend not to provide the most efficient (GLS) estimator but rather LS estimates (an exception is FERTIG (1999)).

We have argued here that discrepancies in the demographic structure of source and destination countries might be an important, perhaps the crucial driving force behind migration. Yet, demographic characteristics of the source countries are hardly a prominent factor in the existing studies. If demographic and economic factors are highly correlated, using economic predictors might alleviate this problem somewhat - but in terms of explaining migration flows, accepting this argument raises a critical shadow of doubt on existing estimates. The existing evidence also suggests that there is considerable temporal persistence in the process, although none of these studies (except FERTig (1999)) modeled cyclical variation in migration activity which affected origin countries together.

Moreover, since prediction was not the major objective of most of these studies, their potential as the basis of such predictions is in doubt. Specifically, it was the declared aim to provide a maximal fit to the historical data, leading to a relatively large set of conditioning variables. Not only will a good within-sample fit not necessarily guarantee a satifactory predicitve performance out-of-sample, but predictions of migration rates will require 
predictions of the conditioning variables. The large set of controls included in these studies will make this task extremly difficult. This problem will be relatively moderate though, if the set of conditioning variables is exclusively demographic - demographic developments can usually be predicted relatively well, since most people present tomorrow have typically been born in this country already today.

\section{Prediction of Future Migration Flows to Germany}

This section develops our own approach to the problem of predicting future migration streams from Eastern Europe to the West within a unified Europe, including the first-round accession candidates, i.e. Czech Republic, Estonia, Hungary, and Poland. The first subsection briefly describes the Eastern European countries with a special emphasis on demographic developments. Finally, subsection 3.2 outlines the utilized model and describes the employed estimation technique.

\subsection{The Crucial Role of Demographics}

In a legal framework like that of the European Union with only small institutional barriers to internal migration, demographics are a major determinant of immigration streams. For a discussion of the potential size as well as the ensuing impact of immigration it is therefore necessary to take into account demographic factors. Germany for instance experienced a substantial inflow in the post-1950 era (e.g. Schmidt And Zimmermann (1992)). Gross immigration amounted to 25.5 million up to 1990, and net migration was around 10 million people. In addition, after 1990 with the demise of communism in Eastern Europe and the civil wars in former Yugoslavia a remarkable inflow of "ethnic Germans" (Aussiedler) and war refugees was added. Demographic aspects have played an important role in this impressive immigration record for two reasons.

First, there has been a remarkable life-cycle pattern in the influx of immigrants to Germany (cf. SCHMIDT (2000)); many immigrants have been 
young adults. In addition, during the first years of the post-1950 era most of the net migration comprised males, thereby confirming the view of the typical migrant being a young male worker. This observation is a direct reflection of the fact that Germany actively recruited so-called guest workers which were typically young males. While the age structure of the influx has changed over time, particularly after the halt in active recruitment in 1974, this observation nevertheless emphasizes that migration activity is crucially determined by the size of young cohorts at the origin. This general conclusion is unlikely to change when considering future migration potential from the EU accession candidates. Thus, in our own approach to its prediction, we concentrate on the characterization of the size of the population at these origins, specifically among more recent cohorts.

Second, these relatively young immigrants displayed a higher survival rate than the relatively old indigenous population. Moreover, even if one assumes that fertility rates are not higher for migrants than for natives of the same birth cohort, the fact that the largest part of the migrant population is in prime childbearing age has contributed substantially to the growth of the migrant population over time (cf. SCHMiDT (2000)). Potentially, there might be an important dynamic impact of this migrant stock on future immigration to be expected. However, as the following discussion demonstrates, its direction is indeterminate, suggesting to start the prediction exercise with a static model of migration.

Past immigration flows and the resulting stock of immigrants in a specific destination country may have several implications for the individual migration decision and, therefore, current migration flows. A part of the literature on the migration decision tries to take into account so called network effects. If people already living in a foreign country help their friends and relatives to get started, e.g. in finding accommodation or jobs, this effect would induce chain migration. This hypothesis might be captured empirically by the stock of previous immigrants to a country. Several empirical papers indeed suggest that there has been a positive effect of previous migration on contemporary migration. However, network effects are not the only possible interpretation for this pattern. For instance, as already pointed out by GrEEnwOOD (1975), the stock of migrants could also be seen as a proxy for an informal information flow between the sending country and the potential destination countries. 
One could imagine that for a potential migrant there are two principal channels of information flows concerning the economic opportunities at the destination. One channel are the publicly available statistics on official unemployment rates and per-capita income provided by the statistical offices or the media, while the second comprises informal information by compatriots already living in the possible target country. While the official statistics are certainly a good starting point for the formation of expectations on the economic prospects at the destination, they rarely reflect the relevant opportunities accurately, especially if skills acquired at the origin are not fully transferable to the destination country. In Germany, for instance, new immigrants are competing with low-skilled native workers and previous immigrants in a small range of occupations where unemployment is higher than the national average (cf. e.g. SCHMIDT (1997)). This implies that their employment prospects would be overestimated by the average unemployment rate and that informal information flows could very well lead to a reduced migrant influx as the population of compatriots accumulates over time.

Thus, the relationship between size and structure of the immigrant population at the destination and prospective migrant influx is intricate. Moreover, a closer look at cohort specific emigration rates (cf. BAEVRE ET AL. (2000) for the case of Norwegian emigration) suggests that there is a negative effect of emigration of members of one cohort on future emigration from the same cohort. This observation is in line with the hypothesis that the propensity to migrate may be heterogenous and the individuals with the highest propensity are migrating first. Alternatively, the emigration of a part of a cohort reduces the labor market competition for the stayers and reduces their incentives to migrate ${ }^{6}$. On balance, these arguments suggest a conservative approach to the prediction of future migration flows which de-emphasizes the dynamic impact of previous on current immigration.

Both the general historical evidence (cf. Plakans AND Wetherell (1995)) and these observations on the specific case of post-WW II Germany have induced us to pursue a modeling strategy emphasizing demographics while absorbing the - slowly changing over time and difficult to predict - economic differences between origin and destination regions into region-specific factors, and an autocorrelated error-component common to all origins. Most importantly, following the received literature in trying to explain observed 
aggregate migration flows mainly by economic variables, like differences in per-capita incomes, while omitting demographics, might not be very promising. These variables typically reflect economic opportunities of average natives at the origin and at the destination, not of those individuals facing the migration decision.

Moreover, differences in economic opportunities are relevant only to a fraction of the population, that in the core age-group of migration. In the extreme, very large cross-country differences in economic opportunities might not induce any migration worth mentioning, if the population in the origin region mostly comprises old men and women. What we therefore suggest to use instead of the usual migration rates are core age migration rates, describing migration activity only among the young. Alternatively, we will use age structure as a regressor in the empirical model, thereby probing the robustness of our predictions. Before we proceed to develop our parsimonious model of migration, we will briefly characterize the demographic structure of the prospective EU accession countries.

The most likely candidate countries for the first round of EU enlargement towards Central and Eastern Europe are the three Eastern European NATO members Czech Republic, Hungary and Poland as well as one Baltic country, Estonia. These four countries (henceforth denoted as $C E E C$-4) currently comprise some 60 million inhabitants and are quite heterogeneous in their economic and demographic characteristics. They also exhibit remarkable differences compared to Germany. Most importantly, post-WW II population dynamics as well as WW II itself have left their imprint on the population age structure of these countries (cf. also SCHMIDT (1996)).

Whereas Germany experienced a decade of high birth rates in the late 1950's and early 1960's, the CEEC-4 experienced such a baby-boom directly after the end of WW II. Therefore, at the end of the 20th century the population age distribution varies considerably between possible origin countries and the potential destination of migrant flows. For 1993 (1990 for Germany) Figure 1 documents a relatively high proportion of people in the age group [20-29] for Germany, while the CEEC-4 display substantially higher population shares among the very young $[<20]$. These cohorts and their children will be the prime candidates for the migration to the West that might be expected after EU enlargement. 
Figure 1: Population by Age Groups - CEEC-4 vs. Germany (around here)

Moreover, whereas mortality rates remained relatively stable during the 1990's (cf. United NATiOns (1996)), there was a remarkable decline in birth rates in the beginning of the 1990's for all of the CEEC-4, thereby moderating future migration pressure. In our predictions we will try to defend ourselves against a downward bias in predicted migration flows and predict the CEEC-4 population into the future using relatively high fertility rates (see below). It is the predicted (young) population at the origin that, together with our estimates of migration rates will then lead to predicted migration flows.

The considerable differences in economic indicators between the four accession candidate countries and Germany as well as among the CEEC- 4 themselves, have led some economists to conclude that there is a vast migration potential in the CEEC-4 just waiting for the starting signal to launch their march to the West and especially to Germany (cf. the controversial views in Bauer and Zimmermann (1999), Fertig (1999), and Sinn (1999), $(2000))$. By contrast, economic differences and their certainly imprecise predictions into the future are not discussed at length in this contribution, releaving us from the requirement to construct convergence scenarios between East and West.

Rather, we utilize our arguments on the crucial role of demographic factors for our predictions which enables us to assess the migration potential without a large range of daring assumptions on the evolution of conditioning variables. Implicitly, this presumes that economic differences are either persistent enough in the short- and medium-term to be absorbed in the country-specific intercept of the migration rate equations or are correlated enough to be absorbed by the time varying error component. The convincing choice of the country-specific intercept for countries for which no previous migration record exists is therefore the principal conceptual challenge for the prediction - yet, this has not been adressed formally in any of the previous papers on this topic. 


\subsection{Theoretical Model and Alternative Identification Assumptions}

We will prepare the empirical application by the formulation of a generic model of aggregate migration flows to a single destination as a frame of reference. Within this framework we are then able to discuss a variety of identification assumptions and corresponding specifications of the model. The simplest conceivable model of aggregate migration rates would be in terms of orthogonal country- and time-specific components, drawn from a common distribution of effects, respectively. In such a variance-components model (in a different context, a similar model is employed by ASHENFELTER AND CARD (1985)) the migration rate $m_{s, t}$ in the relevant age range for origin country $s=1, . ., S$ and period $t=1, \ldots, T$, consists of an overall intercept term $\mu$, a random component specific to country $s$ but persistent over time $\epsilon_{s}$, a component specific to time periods but relevant for all countries at this point in time $\epsilon_{t}$, and an unpredictable white noise error term $\epsilon_{s, t}$.

In effect, we have

$$
m_{s, t}=\mu+\epsilon_{s}+\epsilon_{t}+\epsilon_{s, t} .
$$

The country-specific component $\epsilon_{s}$ captures all aspects of the process determining migration from $s$ to the destination country which tend to persist over time, such as a common (colonial) history, climate and distance, a common language or border but also persistent economic differences. This formulation enables us to characterize the distribution from which the country-specific intercept term of those future migration countries is chosen for which no previous immigration record is available.

The period-specific component $\epsilon_{t}$ reflects all determinants of migration activity which vary over time but operate in all countries identically during the same period. A case in point could be any fluctuations in economic activity in the destination country, for instance in aggregate labor demand. Even in this basic model we would be very hesitant to exclude correlation of this factor across periods. Modeling the autocorrelation of this factor will there-

fore be central to our application. Specifically, we will model this process as an autoregressive process of first order. In brief, the stochastic structure of the process (there are naturally no correlations across the variance 
components) is

$$
\epsilon_{s} \sim\left(0, \sigma_{s}^{2}\right), \epsilon_{t} \sim\left(0, \sigma_{t}^{2}, \rho\right), \epsilon_{s, t} \sim\left(0, \sigma_{s, t}^{2}\right)
$$

In our empirical work we will solve the estimation problem by using Method of Moments techniques. Intuitively, the idea behind Method of Moments is estimating the unknown parameters by matching the theoretical population moments, which are functions of the unknown parameters, with the appropriate sample moments (HARRIS AND MATYAS (1998)). Formally, the first step in this endeavour is to define the moment conditions. We want to estimate from our observed sample $\left\{m_{s, t} ; s=1, \ldots, S ; t=1, \ldots, T\right\}$ a $p \times 1$ vector $\theta$ of unknown parameters with true value $\theta_{0}$. If $f\left(m_{s, t}, m_{s^{\prime}, t^{\prime}} ; \theta\right)$ denotes a continuous $q \times 1$ vector function of $\theta$ and $E\left(f\left(m_{s, t}, m_{s^{\prime}, t^{\prime}} ; \theta\right)\right)$ exists and is finite for all $s, s^{\prime}, t, t^{\prime}$ and $\theta$, then $E\left(f\left(m_{s, t}, m_{s^{\prime}, t^{\prime}} ; \theta_{0}\right)\right)=0$ are the moment conditions.

In our application the vector of unknown parameters is $\theta=\left(\mu \sigma_{s}^{2} \sigma_{t}^{2} \rho \sigma_{s, t}^{2}\right)^{\prime}$ and the moment conditions are

$$
\begin{array}{lll}
g_{0} \equiv E\left(m_{s, t}\right) & =\mu \\
g_{1} \equiv \operatorname{Var}\left(m_{s, t}\right) & =\sigma_{t}^{2}+\sigma_{s}^{2}+\sigma_{s, t}^{2} & \\
g_{2} \equiv \operatorname{Cov}\left(m_{s, t}, m_{s^{\prime}, t}\right) & =\sigma_{t}^{2} & \text { for } s \neq s^{\prime} \\
g_{3} \equiv \operatorname{Cov}\left(m_{s, t}, m_{s, \tau}\right) & =\rho^{|t-\tau|} \sigma_{t}^{2}+\sigma_{s}^{2} & \\
g_{4} \equiv \operatorname{Cov}\left(m_{s, t}, m_{s^{\prime}, \tau}\right) & =\rho^{|t-\tau|} \sigma_{t}^{2} &
\end{array}
$$

The moment conditions $g_{3}$ and $g_{4}$ imply that the covariance of migration rates over time jointly reflects country-specific variation and persistence of the process. If one restricted $\rho$ to zero, all this covariance would be attributed to country-specific effects.

Let $u_{s, t}=f\left(m_{s, t}, m_{s^{\prime}, t^{\prime}} ; \theta_{0}\right)$ denote the Method of Moments disturbance and assume that $\left\{m_{s, t}\right\}$ is a stationary process. Let $f_{S, T}(\theta)=(S T)^{-1} \sum_{s=1}^{S} \sum_{t=1}^{T}$ $f\left(m_{s, t}, m_{s^{\prime}, t^{\prime}} ; \theta\right)$ denote the sample moments corresponding to the moment conditions and define the criterion function $Q_{S, T}(\theta)=f_{S, T}(\theta)^{\prime} A f_{S, T}(\theta)$, where $A$ is a stochastic positive definite matrix. Then the Generalized Method of Moments (GMM) estimator of $\theta$ is

$$
\hat{\theta}_{S, T}=\operatorname{argmin}_{\theta} Q_{S, T}(\theta)
$$


Given a number of assumptions (HARRIS AND MATYAS (1998), p. 11-21) the GMM estimator is weakly consistent and asymptotically normally distributed.

If the number of moment conditions is equal to the number of parameters to be estimated, the above system is exactly identified. Then the GMM estimator does not depend on the choice of the distance matrix $A$ and collapses to the Method of Moment estimator. However, if the system is overidentified, i.e. if $q>p$, different GMM estimators are obtained for different distance matrices. The choice of the distance matrix that results in an asymptotically efficient GMM estimator is the long-run covariance matrix $V$ of the GMM disturbance $u_{s, t}$. Given this choice of the distance matrix $\sqrt{S T}\left(\theta_{S, T}-\theta_{0}\right)$ has an asymptotic normal distribution with mean zero and covariance matrix $\left(F^{\prime} V^{-1} F\right)^{-1}$, where $F$ denotes the matrix of derivatives of the moment conditions with respect to the parameters.

With a consistent estimator $\hat{V}$ for $V$ in hand one will be able to obtain $\hat{\theta}_{S, T}$ by setting $A=\hat{V}^{-1}$. The resulting estimator is called the optimal or efficient GMM estimator given $f\left(m_{s, t}, m_{s^{\prime}, t^{\prime}} ; \theta\right)$. The estimated standard errors of this optimal GMM estimator are then obtained as the square roots of the diagonal elements of $(S T)^{-1}\left\{F_{S T}^{\prime} \hat{V}^{-1} F_{S T}\right\}^{-1}$. Furthermore, given the optimal choice of the weighting matrix the resulting value of the criterion function can be used as a test statistic for the detection of mis-specification, since $(S T)^{-1} Q_{S, T}(\hat{\theta})$ is asymptotically distributed as $\chi^{2}$ with the number of overidentifying restrictions as the appropriate degrees of freedom. In our application, we estimate the long run covariance matrix $V$ as a diagonal matrix using the empirical moments in the sample.

\section{Estimation Results and Forecasting Scenarios}

On the basis of our Western data for the post-WW II period, we will now estimate the historical relationship between migration to Germany and its aggregate-level demographic determinants, and use these estimates to generate concrete predictions of the immigration flows from Eastern Europe 
following EU enlargement. To explore the robustness of our predictions we will contrast three different specifications of our model. In a first specification, we model the overall migration rate (the migrant flow relative to the population at the origin) using our most parsimonious variance--components formulation.

A second specification concentrates on the population of core age (less than 39 years of age), retaining the parsimonious empirical specification. This strategy requires that we prepare the estimation by a careful transformation of the available data. Finally, the time-varying age structure in the various origin countries is used as a regressor parameterizing the mean migration rate $\mu$. In all variants of the model we contrast exactly identified and overidentified specifications. Before we proceed to reporting our estimation results, we briefly introduce the data material and the preliminary data transformations necessitated by our approach.

\subsection{Data and Variable Construction}

Our sample consists of observed migration streams from 17 countries of origin (Austria, Belgium, Switzerland, Denmark, Spain, Finland, France, Greece, Italy, Yugoslavia, Netherlands, Norway, Portugal, Sweden, Turkey, United Kingdom, and USA) for the time period covering 1960 to 1997. Therefore, the number of observations is 646 . Immigration figures comprise inflows and outflows of foreigners only, while the flows from and to the numerically negligible CEEC-4 were excluded from the sample. In effect, we have to predict the net migration from the CEEC-4 not only out of the temporal sample experience, but also out of the realm of the observed origin countries. Since the data only comprises foreigners, for the years after 1990 the substantial inflow of ethnic Germans (Aussiedler) is not taken into account. The migration data stems from German Federal Statistical Office (Statistisches Bundesamt), which also provides information on the population by birth cohorts in Germany. Population data for the sample countries as well as the CEEC-4 is reported in the Demographic Yearbook published annually by the United Nations.

In our estimations we utilize two different dependent variables. In a first variant we use the standard net migration rate, i.e. net migration from coun- 
try $s$ in year $t$ divided by the stock of population in the respective country and year, as dependent variable. In a second variant, following our reasoning outlined above, the dependent variable is the "age adjusted" net migration rate, i.e. the flow of migrants from $s$ at time $t$ in the core age group (0 to 39 years of age) divided by the population in $s$ and $t$ in this age group. These migration rates, however, are neither observable directly nor can they be constructed from the available official statistics. Therefore, we employ a simple population accounting approach which enables us to construct such rates.

Specifically, immigration figures have generally been recorded as an aggregate over all ages. To calculate the number of immigrants from any particular country of origin, we would like to correct observed overall influx from that source country by an appropriate correction factor lying between 0 and 1 and varying over time. While we are not be able to separately construct such a correction factor for each origin country, we are able to offer an estimate of the aggregate net influx by age for each individual year of the sample period (cf. SchmidT (2000) for details). The desired time-varying correction factor is derived by tracking individual birth cohorts through time in a variant of the life-table survival method. Abstaining from distinguishing natives and migrants along any other dimension than age and gender, this method applies a life-table to a census count to project survivors at either past or future time points.

The difference between the projected number of survivors and the enumerated population at that time is then taken as the estimated net migration, with an estimated migration figure for each individual year of age. The net immigration measured for each individual birth cohort in the sample range can then be accumulated appropriately for each year $t$ to estimate the net immigration in a certain age range. Since mortality only changes slowly over time, the survival probabilities are taken from the 1970/72 lifetable for Germany and, thus, describe most accurately the middle of the observation period. In the calculations, identical conditional survival probabilities are applied to natives and migrants already present in the destination country. The primary basis for the population data employed here are the census waves of 1950, 1961, 1970, and 1987. Annual data are updates based on community registers of births, deaths and relocation. 
For both dependent variables the variance components-model of section 3 is estimated by the Generalized Method of Moments. In addition, in the model for the standard migration rate, the constant overall intercept is parameterized in a third variation of the model as a linear function of the share of young inhabitants (0-39 years) in the various origin countries yielding a sixth parameter $\beta$ to be estimated. In all three cases, the estimation procedure comprises two different specifications. Firstly, we estimate an exactly identified system, where we chose five (six) moment restrictions in order to estimate the five (six) unknown parameters of the model. Secondly, we overidentify the system by imposing two (one) additional moment restrictions, thus yielding seven moment restrictions for the estimation of five (six) parameters. Obviously, the criterion function evaluated at the final estimates need not necessarily yield a value of zero. Therefore, one has to test whether these additional overidentifying restrictions hold in the data.

\subsection{Parameter Estimates}

GMM estimation results for the standard migration rates as dependent variables are reported in Table 2. The first column shows the results for the exactly identified system whereas results for the overidentified system are reported in the last column. Our interpretation and our simulations (see below) will focus on the overidentified model.

Table 2: GMM results - standard migration rates $(\times 100)$ (around here)

The average migration rate for the typical origin country during the sample period was approximately 0.03 percent of its population. Around this average value, we observe a substantial fluctuation across space and time with all variance components being estimated quite precisely. The countryspecific variance component is estimated to account for more than a third of the overall variation, despite allowing for persistence in the temporal error component.

By contrast, this variance component being common to all countries is estimated to be relatively small in magnitude, although the large value of the autoregressive parameter indicates that any shock to aggregate migration activity typically has a long-lasting impact. Close inspection of the predicted 
values of the time-specific component over the sample period indicates that migration activity to Germany was relatively low at the end of the 1990's. Finally, the computed value 4.22 of the test statistic implies that the null hypothesis that the overidentifying restrictions hold is not rejected at any reasonable level of significance.

Table 3: GMM results - "age adjusted" migration rates $(\times 100)$ (around here)

The results of the GMM estimation with the "age adjusted" net migration rates as dependent variable are reported in Table 3. Again, the first column contains the exactly identified and column two the overidentified model. As was to be expected, the overall average of the migration rate among the young is relatively high, approximately 0.04 percent. Estimation results for the variance components are qualitatively very similar to those reported in the previous table, and are again estimated quite precisely. The countryspecific component accounts for approximately one third of the overall variance, the time-specific component is of relatively minor magnitude but of remarkable persistence. Again the overidentification test indicates a satisfactory performance of the model specification.

Finally, Table 4 reports the results of fitting a third specification to the data which parametrizes the overall constant to be a linear function of the share of young individuals (0-39 years of age) in the population. Of course, the average migration rate is again estimated to be 0.03 percent for a country with the typical age-structure (almost 60 percent being younger than 40). Any origin country whose age structure deviates by the share of younger individuals being, say, 5 percentage points higher than the average, will typically display an increase in its migration rate to almost 0.06 percent.

Table 4: GMM results - age--share as regressor $(\times 100)$ (around here)

The importance of the country-specific variance component is only slightly reduced in these estimates, indicating relatively persistent age-shares during the sample period. No substantial impact can be detected on the estimate of the persistence parameter as well. Overall, these results seem suffciently stable to serve as the basis for our predictions. In particular, the variation captured by the variance components implies that the location of any 
prospective origin country in the distribution of country-specific effects will be decisive for the predicted accumulation over time of migration flows from that source. The temporal component will - due to its negative value at the end of the sample period - likely dampen prospective migration flows for several years to come. To ward off any downward bias in our predictions, we will disregard this dampening factor in our simulations.

\subsection{Forecasting Scenarios}

Our approach identifies the overall population size in the CEEC-4 and its age-structure as the principal driving forces of future migration to Germany. To predict future migration flows, we therefore need the projected population size and age structure for these countries. Starting from the current age structure, we again construct these demographic projections using the German life-table of 1970/72, ignoring any loss of population due to emigration, and predicting the birth of future cohorts according to a common set of age-specific fertility rates. Specifically, it is assumed that reproduction rates in the CEEC-4 do not differ substantially from that observed for a typical cohort of post-WW II German women, the cohort born in 1936, which started its reproduction around 1950 and continued up to approximately 1984 .

While initially the Polish population is relatively young, indicating a relatively high migration potential, that of Hungary is relatively old, with Estonia and the Czech Republic being somewhere in between. Neither country displays a spectacularly high share of young individuals, and the overall development is towards an ageing population, a phenomenon quite familiar from Western economies. Our particular choice of demographic parameters is likely to over-predict the young population. In our projections we combine this predicted age structure for each year 1998 to 2017 with our estimated parameters reported in the previous section.

Since the CEEC-4 have no previous record of migration to Germany, choosing the likely location of the country-specific intercepts in the distribution whose variance has been estimated from the data for those countries which actually had such a migration record is of crucial importance for the validity of the results. To explore the impact of different invariance assumptions, we compare scenarios for the "typical country" with $\epsilon_{s}=0$ with a 
"high-emigration" country whose value of $\epsilon_{s}$ is determined as plus one standard deviation apart from the typical country.

For both principal scenarios we predict migration to Germany over the period 1998 to 2017 using the standard migration rates applied to overall population (scenarios I and IV in Table 5) and to the overall population and age--structure (scenarios III and VI), and using the age-adjusted migration rates (scenarios II and V). Using the latter implicitly assumes that it is only the net migration of the young that is of importance in the future, and that the migration of old individuals that we observe in the historical data exclusively reflected the specific institutional setting before the turn of the century.

Table 5: Summary of Forecasting Scenarios 1998-2017 (around here)

Irrespective of the particular specification chosen for the predictions, it is the choice of the country-specific component that is decisive for the magnitude of the forecasts. If the CEEC-4 behaved as a typical source country for the migration to Germany, annual net migration for all four countries taken together would fluctuate around 15 to 18 thousand individuals during the forecasting period, leading to an accumulated figure of 300 to 400 thousand people by 2017. By contrast, if it were a high-emigration region, between 49 and 63 thousand people would arrive in Germany - net of countervailing emigration flows - each year, leading to an accumulated influx of between 900 thousand and 1.2 million people.

Although this figure is much higher than those of the scenarios I to III, it nevertheless seems moderate when compared to the high figures that fuel the public debate on this issue. While we explicitly refrain from any more concrete speculation on the impact that the large initial differences in economic prosperity between the CEEC-4 and the rest of the EU might have on the country-specific components to be realized, the high-immigration scenarios are likely to provide an upper bound on what to expect after EU accession of the CEEC-4. 


\section{Concluding Remarks}

In this paper, we have reviewed aggregate-level migration studies with a particular emphasis on their potential and their limits as tools for forecasting future migration streams. As we have emphasized, the task of assessing migration potential and predicting future migration flows requires strong identification assumptions to hold, particularly when following the usual approach of fitting a relatively saturated specification to the observed migration data, typically including a substantial number of economic variables on the right-hand side of the regression. Over and above the necessary assumptions of temporal stability of the behavioral relationships, one has to have a relatively precise notion about the development of these conditioning variables in the future. Unfortunately and in contrast to key demographic variables, economic variables are notoriously difficult to predict.

Moreover, whenever a new origin region enters the scene, the extrapolation exercise has to extend from predictions out of the sample horizon to predictions out of the spatial realm of experience. This requirement is an almost prohibitive challenge to any saturated model of aggregate migration intensity. The specific application that our paper addresses is the prediction of migration flows to be expected from the most likely accession countries in Eastern Europe. No previous migration record to Germany exists for these countries that can be used to gauge future emigration propensities from these countries, once they were to enjoy the freedom-of-movement privileges held by other EU member countries. Consequently, it hardly seems surprising that current predictions of the expected migration flows from these countries appear to vary widely.

In developing our own approach to the problem, we depart from the received migration literature - whose emphasis is typically on the explanation of migration activity, not its prediction into the future - and pursue a very parsimonious specification of migration rates that is fitted to historical data on the German post-WW II immigration experience. Its formulation explicitly allows for persistent economic and non-economic differences to be captured by a set of country-specific random effects which, together with a time-specific and a white noise component drive the fluctuation of migration rates around its average across time and space. The relative magnitudes of these unobserved orthogonal variance components lends itself naturally to a 
discussion of the prediction problem raised by EU enlargement.

Specifically, if the new EU members were to display the emigration behavior to Germany that has characterized the typical origin country during the (high-immigration) post-WW II era, prospective net immigration would be of almost negligible magnitude. If, by contrast, they were to display a substantially more pronounced emigration propensity, future net immigration could be much larger, albeit still relatively moderate when considering the figures circulating in the public debate on this issue. Notably, while the proponents of large migration forecasts are likely to emphasize the large economic differences between the prospective EU members and the existing member states, it is very difficult to predict - if it materializes at all - the pace of any economic convergence towards the EU average within the next two or three decades. Moreover, the existing migration literature does not at all provide a convincing body of evidence for the actual relevance of economic variables to migration activity. At best, this evidence is mixed. It is also quite likely that the large economic discrepancies are balanced to some degree by considerable migration cost.

Most importantly, our approach to the problem emphasizes the crucial role of demographics for what is primarily a demographic process. It is the size of the population in the origin region, and particularly the size of the young population which is of principal importance for the expected migration flows. Large fluctuations in economic differences would exert little impact on migration activity, if the population in the source regions were to be old, a simple truth that seems to be neglected in many migration forecasts. Thus, in combining the estimates from our parsimoniously specified model for the aggregate migration rate with the projected population size and structure in the prospective EU member countries, we have exploited the fact that demographic circumstances can be predicted relatively precisely into the future. To assess the robustness of our forecasts to a variation of the model structure we have pursued several specifications and several forecast scenarios, all yielding qualitatively similar results. If our emphasis were on explaining past migration behavior, rather than forecasting into the future and into different spatial circumstances, we would of course have pursued less parsimonious specifications, a task that we leave to future research. 


\section{Endnotes}

${ }^{1}$ There are two prominent alternatives to this approach: (i) using intentions data (e.g. PApapaganos et. Al. (2000), Bauer And Zimmermann (1999)) - since it is the manifestation of intentions, not some verbal account of desires, which are at issue, this approach risks being very unreliable; (ii) inference based on historical precedent - very rarely will it be possible to detect a closely comparable situation in historical data, however, making it very likely that this approach remains anecdotal.

2 These differences are caused by underlying forces such as - among others - participation in wars (see for instance the comparison of Germany, Poland and Sweden, and the effect of WW II on their respective population age structure in SCHMIDT (1996)), differences in the system of education and public health (in developing countries, education of the mother is a prime determinant of fertility and child mortality, and child mortality is still substantially different from that in the OECD), or differences in tax or social security systems.

3 The received literature frequently pays particular attention to the distinction of economic and non-economic migrants, with the latter comprising migrants pursuing family re-unification and political and war refugees. Our argument applies to voluntary migration.

4 Needless to say that this precludes a separate inclusion of countryspecific effects.

${ }^{5}$ Country fixed effects are a problem for forecasting future streams from countries not being in the sample. However, this problem may be solved by modeling these effects directly (see below) or by a two-step procedure whose second step re-parameterizes the estimated intercepts by a set of timeinvariant regressors (FERTIG (1999)).

${ }^{6}$ A similar approach for southern European migration flows is adopted by (FAini AND VENTURini (1994)). 


\section{References}

Ashenfelter, Orley and David Card (1985), Using the Longitudinal Structure of Earnings to Estimate the Effects of Training Programs. The Review of Economics and Statistics, 67, 648-660.

Baevre, Kare, Christian Rits and Tore Thonstad (2000), Norwegian Cohort Emigration. Journal of Population Economics (forthcoming).

Bauer, Thomas and Klaus F. Zimmermann (1999), Assessment of Possible Migration Pressure and its Labour Market Impact Following EU Enlargement to Central and Eastern Europe. A Study for the Department for Education and Employment.

Dustmann, Christian and Christoph M. Schmidt (2000), The Wage Performance of Immigrant Women: Full-Time Jobs, Part-Time Jobs, and the Role of Selection. mimeo., University of Heidelberg.

Faini, Ricardo and Alessandra Venturini (1999), Migration and Growth: The Experience of Southern Europe. CEPR Discussion Paper No. 964.

Fertig, Michael (1999), The Economic Impact of EU-Enlargement: Assessing the Migration Potential. University of Heidelberg, Department of Economics, Discussion Paper Series, No. 293.

Greenwood, Michael J. (1975), Research on Internal Migration in the United States: A Survey. Journal of Economic Literature, 13, 397-433.

Harris, David and Laszlo Matyas (1999), Introduction to the Generalized Method of Moments Estimation. In: Matyas, L. (ed.), Generalized Method of Moments Estimation. Cambridge: Cambridge University Press, 3-30.

Harris, J.R. and M.P. Todaro (1970), Migration, Unemployment and Development: A Two-Sector Anaylsis. American Economic Review, 60, 126142. 
Karras, Georgios and Carmel U. Chiswick (1999), Macroeconomic Determinants of Migration. The Case of Germany: 1964-1988. International Migration, 37, 657-677.

Katseli, Louka T. and Nicolas P. Glytsos (1986), Theoretical and Empirical Determinants of International Labour Mobility: A Greek-German Perspective. In: Gordon, I. and A. P. Thirlwall (eds.), European Factor Mobility. Trends and Consequences. MacMillan Press, 95-115.

Papapaganos, Harry and P. SAnfey (2000), Intention to Emigrate in Transition Countries: The Case of Albania. Journal of Population Economics (forthcoming).

Plakans, Andrej S. and Charles Wetherell (1995), Migration in the Later Years of Life in Traditional Europe. In: KerTzer, DAVID I. and Peter Laslett (eds.): Aging in the Past: Demography, Society, and Old Age. Berkeley et. al.: University of California Press, 156-174.

Ravenstein, E. (1889), The Laws of Migration. Journal of the Statistical Society, 52, 214-301.

Rogers, Andrei and Louis J. Castro (1986), Migration. In: Andrei Rogers and Frans J. Willekens (eds.): Migration and Settlement: A Multiregional Comparative Study. Dordrecht: D. Reidel, 157-208.

SChmidt, Christoph M. (1996), Cohort Sizes and Unemployment: Lessons for Poland. In: Hartmut Lehmann and Jonathan Wadsworth (eds.): Labor Markets by Design?, Ifo Studies on Eastern Europe and the Economies of Transition, 21, 126-154.

Schmidt, Christoph M. (1997), Immigrant Performance in Germany: Labor Earnings of Ethnic German Migrants and Foreign Guest-Workers. The Quarterly Review of Economics and Finance, 37, 379-397.

Schmidt, Christoph M. (1999), Knowing What Works - The Case For Rigorous Program Evaluation. IZA Discussion Paper No. $7 \%$. 
Schmidt, Christoph M. (2000), Reconstructing Germany: The Demographic Impact of Immigration During the Post-War Era. mimeo., University of Heidelberg.

Schmidt, Christoph M. and Klaus F. Zimmermann (1992), Migration Pressure in Germany: Past and Future. In: Klaus F. Zimmermann (ed.): Migration and Economic Development. Berlin: Springer, 207-236.

Sinn, Hans-Werner (1999), EU Enlargement, Migration, and Lessons from German Unification. CESifo Working paper Series No. 182.

Sinn, Hans-Werner (2000), EU Enlargement, and the Future of the Welfare State. CESifo Working paper Series No. $30 \%$.

SjaAstad, LARry A. (1962), The Cost and Returns of Human Migration. Journal of Political Economy, 70, 80-93.

United Nations (1996), Demographic Yearbook 1994. Department for Economic and Social Information and Policy Analysis, 46.

Vogler, Michael and Ralph Rotte (2000), The Effects of Development on Migration: Theoretical Issues and New Empirical Evidence. Journal of Population Economics (forthcoming).

Zimmermann, Klaus F. (1991), Ageing and the Labour Market. Journal of Population Economics, 4, 177-200. 
Table 1: Existing studies of aggregate migration flows to Germany

\begin{tabular}{|c|c|c|c|c|}
\hline Author(s) & Katseli and Glytsos (1986) & Karras and Chiswick (1999) & Fertig (1999) & Vogler and Rotte (2000) \\
\hline Dependent variable & Gross migration rate & Net migration rate & Change in net migration rate & $\begin{array}{l}\text { Log of gross rates and } \\
\text { asylum seeker rates }\end{array}$ \\
\hline PCI in origin country & 0 & & & + (level); - squared level \\
\hline PCI in Germany & 0 & & & \\
\hline Relative PCI & & 0 & $+($ level and change) & + \\
\hline Growth of GDP in Germany & & + & & + \\
\hline $\begin{array}{l}\text { Growth of GDP in origin } \\
\text { country }\end{array}$ & & - & & \\
\hline $\begin{array}{l}\text { Unemployment rate in } \\
\text { origin country }\end{array}$ & + & & + (level and change) & \\
\hline $\begin{array}{l}\text { Unemployment rate in } \\
\text { Germany }\end{array}$ & - & & - (level and change) & \\
\hline $\begin{array}{l}\text { Lagged dependent variable } \\
\text { Stock of migrants in } \\
\text { Germany }\end{array}$ & 0 & + & $\begin{array}{l}-(\text { level }) \\
0\end{array}$ & \\
\hline Other variables & 0 Remittances & + Mean schooling & $\begin{array}{l}+ \text { EU dummy; } \\
0 \text { guest worker dummy }\end{array}$ & $\begin{array}{l}\text { 0 Political Terror Scale; } \\
\text { - Civil rights; } \\
\text { + Share of urban population }\end{array}$ \\
\hline Dataset & $\begin{array}{l}\text { Time series for Greek- } \\
\text { German migration } \\
(1961-1983)\end{array}$ & $\begin{array}{l}\text { Pooled cross-section/time- } \\
\text { series mainly for European } \\
\text { countries (1960-1988) }\end{array}$ & $\begin{array}{l}\text { Pooled cross-section/time- } \\
\text { series mainly for European } \\
\text { countries (1960-1994) }\end{array}$ & $\begin{array}{l}\text { Pooled cross-section/time- } \\
\text { series for Asian and African } \\
\text { countries (1981-1995) }\end{array}$ \\
\hline Estimation Procedure & OLS & Pooled OLS & ML by iterated GLS & $\begin{array}{l}\text { Fixed and random effects } \\
\text { panel estimator }\end{array}$ \\
\hline Identification assumptions & $(1),(2),(3),(5)$ & $(1),(2),(3),(4),(5)$ & $(1),(2),(3)$ & $(1),(2),(3),(5)$ \\
\hline Forecasting & None & None & $\begin{array}{l}\text { Double out of sample for } \\
10 \text { CEEC's }\end{array}$ & None \\
\hline
\end{tabular}

Note: + denotes a significant positive impact on the dependent variable, - a significant negative, and 0 an insignificant effect. 
Figure 1: Population by age groups - CEEC-4 vs. Germany

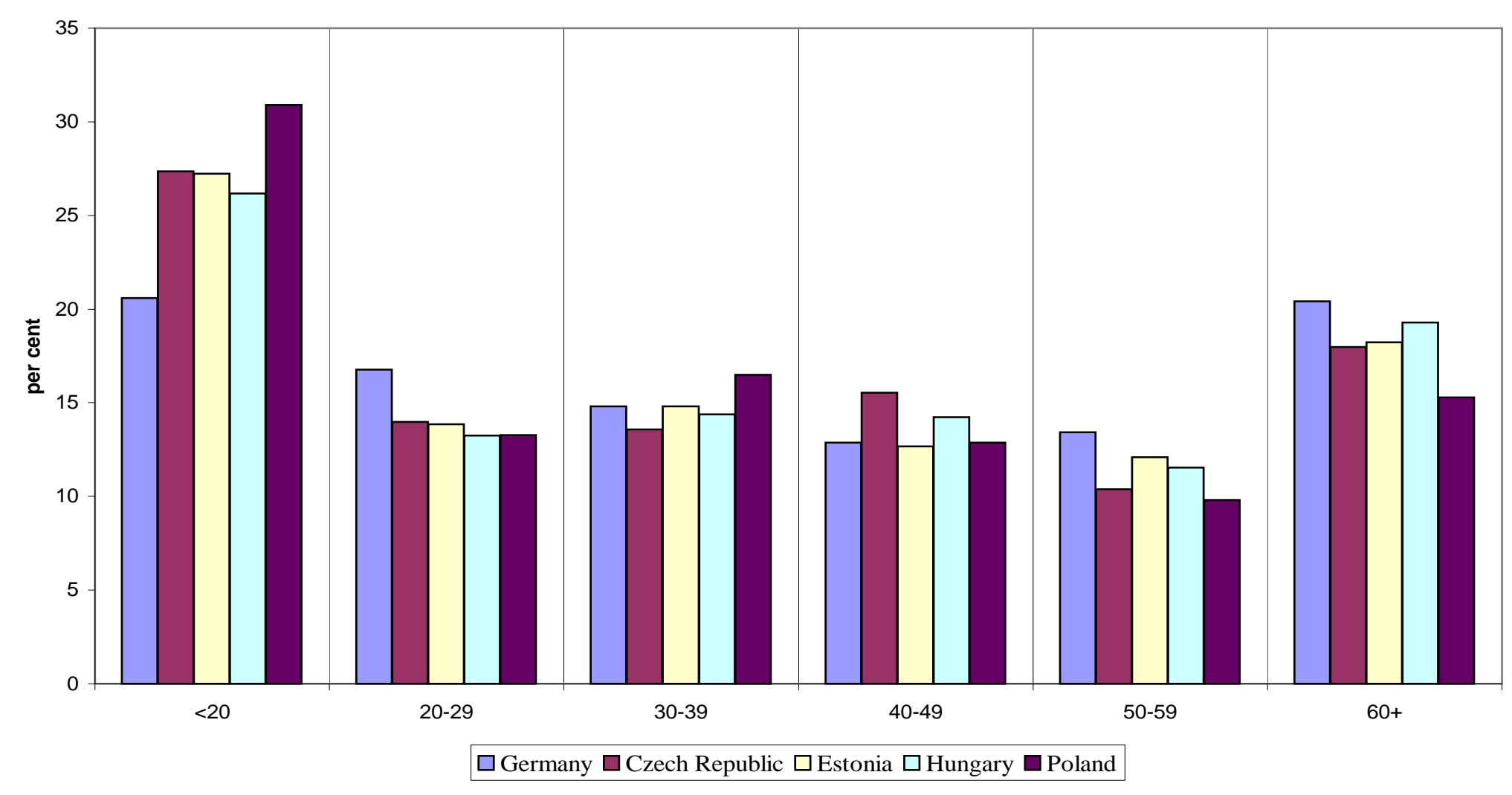

Source: United Nations (1996); own calculations 
Table 2: GMM results - standard migration rates $(\times 100)$

\begin{tabular}{lcc}
\hline \hline & $\begin{array}{c}\text { exactly identified } \\
\text { model }\end{array}$ & $\begin{array}{c}\text { overidentified } \\
\text { model }\end{array}$ \\
\hline Common intercept & 0.029 & 0.029 \\
& $(0.0045)$ & $(0.0045)$ \\
Variance of & & \\
Country-specific component & 0.008 & 0.005 \\
Time-specific component & $(0.0018)$ & $(0.0012)$ \\
Unsystematic component & 0.0022 & 0.0024 \\
& $(0.00062)$ & $(0.00056)$ \\
Persistence parameter & 0.003 & 0.006 \\
& $(0.003)$ & $(0.003)$ \\
Overidentification test & 0.645 & 0.645 \\
& $(0.224)$ & $(0.186)$ \\
\hline
\end{tabular}

Note: Standard errors are reported in parentheses. 
Table 3: GMM results - "age adjusted" migration rates $(\times 100)$

\begin{tabular}{lcc}
\hline \hline & $\begin{array}{c}\text { exactly identified } \\
\text { model }\end{array}$ & $\begin{array}{c}\text { overidentified } \\
\text { model }\end{array}$ \\
\hline Common intercept & 0.041 & 0.041 \\
& $(0.0062)$ & $(0.0062)$ \\
Variance of & & \\
Country-specific component & 0.015 & 0.009 \\
Time-specific component & $(0.004)$ & $(0.0023)$ \\
Unsystematic component & 0.005 & 0.005 \\
& $(0.001)$ & $(0.001)$ \\
Persistence parameter & 0.006 & 0.011 \\
& $(0.006)$ & $(0.005)$ \\
Overidentification test & 0.642 & 0.633 \\
\hline
\end{tabular}

Note: Standard errors are reported in parentheses. 
Table 4: GMM results - age--share as regressor $(\times 100)$

\begin{tabular}{lcc}
\hline \hline & $\begin{array}{c}\text { exactly identified } \\
\text { model }\end{array}$ & $\begin{array}{c}\text { overidentified } \\
\text { model }\end{array}$ \\
\hline Common intercept & -0.254 & -0.254 \\
& $(0.0045)$ & $(0.0045)$ \\
share of core-age pop. & 0.483 & 0.483 \\
& $(0.0005)$ & $(0.0005)$ \\
Variance of & & \\
Time-specific component & 0.008 & 0.005 \\
Country-specific component & $(0.002)$ & $(0.001)$ \\
& 0.002 & 0.002 \\
Unsystematic component & $(0.0006)$ & $(0.0006)$ \\
& 0.003 & 0.006 \\
Persistence parameter & $(0.003)$ & $(0.0026)$ \\
& 0.630 & 0.635 \\
Overidentification test & $(0.235)$ & $(0.192)$ \\
\hline
\end{tabular}

Note: Standard errors are reported in parentheses. 
Table 5: Summary of forecasting scenarios 1998-2017

\begin{tabular}{lc}
\hline \hline Scenario: average annual inflow & accumulated inflow \\
\hline I: standard rates & 17,964 \\
II: age-adjusted rates & 359,285 \\
14,656 & 293,122 \\
III: with age-share as regressor & 301,583 \\
15,079 & $1,253,129$ \\
IV: standard rates plus one std.-deviation \\
$\quad 62,656$ \\
V: age-adjusted rates plus one std.-deviation \\
$\quad 48,551$ & 971,011 \\
VI: with age share as regressor plus one std.-deviation & $1,147,533$ \\
\hline
\end{tabular}

Note: All figures comprise the CEEC-4, i.e Czech Republic, Estonia, Hungary, and Poland. 


\section{IZA Discussion Papers}

No. Author(s)

81

T. J. Hatton

S. Wheatley Price

82

K. A. Konrad

83

R. Euwals

84

C. M. Schmidt

85

S. Pudney

M. A. Shields

86

J.P. Haisken-DeNew

C. M. Schmidt

87

T. K. Bauer

88

O. Bover

P. Velilla

89

S. Neuman

90

H. Lehmann

J. Wadsworth

91

M. Lechner

M. Lechner

94

M. Eichler

M. Lechner

95

P. Cahuc

A. Zylberberg

96

P. Cahuc

A. Zylberberg
Title

Area

Date

Migration, Migrants and Policy in the United

1

$12 / 99$

Kingdom

Privacy, time consistent optimal labor income

3

$12 / 99$

taxation and education policy

Female Labour Supply, Flexibility of Working Hours, 1 and Job Mobility in the Netherlands

The Heterogeneity and Cyclical Sensitivity of 1 Unemployment: An Exploration of German Labor Market Flows

Gender and Racial Discrimination in Pay and 5/6 Promotion for NHS Nurses

Money for Nothing and Your Chips for Free?

The Anatomy of the PC Wage Differential

Educational Mismatch and Wages in Germany

1

Migration in Spain: Historical Background and 1

Current Trends

Aliyah to Israel: Immigration under Conditions of 1 Adversity

Tenures that Shook the World: Worker Turnover in 4

Russia, Poland and Britain

Identification and Estimation of Causal Effects of 6

Multiple Treatments Under the Conditional

Independence Assumption

The Rate of Return to Private Schooling

5

An Evaluation of Public-Sector-Sponsored

6

Continuous Vocational Training Programs in East

Germany

An Evaluation of Public Employment Programmes 6

in the East German State of Sachsen-Anhalt

Job Protection, Minimum Wage and Unemployment 3

Redundancy Payments, Incomplete Labor

3

Contracts, Unemployment and Welfare
$12 / 99$

$12 / 99$

12/99

12/99

$12 / 99$

$12 / 99$

12/99

$12 / 99$

$12 / 99$

$12 / 99$

12/99

$12 / 99$

$12 / 99$

$12 / 99$ 
Matching Model with Uncertainty -

An Extension of Mortensen and Pissarides (1994)
G. Brunello
B. Parigi

Ownership or Performance: What Determines

Board of Directors' Turnover in Italy?

Modeling Financial Incentives to Get Unemployed Back to Work

109 G. J. van den Berg

Combining Micro and Macro Unemployment 
114 G. Brunello

A. Medio

115 A. Cigno

F. C. Rosati

116 C. Belzil

117 S. Bender
A. Haas
C. Klose

118 M. A. Shields M. E. Ward

119 A. Lindbeck

D. J. Snower

120 P. T. Pereira P. S. Martins

J. C. van Ours

D. Munich

J. Svejnar

K. Terrell

123 J. Hunt

124 R. T. Riphahn

125 F. Büchel

J. R. Frick

126 J. Fersterer

R. Winter-Ebmer

127

M. Karanassou

D. J. Snower

128 O. Ashenfelter

D. Ashmore

O. Deschênes

129 B. R. Chiswick M. E. Hurst

130 G. Brunello

S. Comi

C. Lucifora

B. R. Chiswick
An Explanation of International Differences in

Education and Workplace Training

Why do Indian Children Work, and is it Bad for Them?

Unemployment Insurance and Subsequent Job

Duration: Job Matching vs. Unobserved

Heterogeneity

IAB Employment Subsample 1975-1995.

Opportunities for Analysis Provided by the

Anonymised Subsample

Improving Nurse Retention in the British National

Health Service: The Impact of Job Satisfaction on Intentions to Quit

The Division of Labor and the Market for

Organizations

Does Education Reduce Wage Inequality?

Quantile Regressions Evidence from Fifteen

European Countries

Do Active Labor Market Policies Help Unemployed

Workers to Find and Keep Regular Jobs?

Returns to Human Capital under the Communist

Wage Grid and During the Transition to a Market

Economy

Why Do People Still Live in East Germany?

Rational Poverty or Poor Rationality? The Take-up of Social Assistance Benefits

The Income Portfolio of Immigrants in Germany -

Effects of Ethnic Origin and Assimilation. Or:

Who Gains from Income Re-Distribution?

Smoking, Discount Rates, and Returns to

Education

Characteristics of Unemployment Dynamics: The

Chain Reaction Approach

Do Unemployment Insurance Recipients Actively

Seek Work? Evidence From Randomized Trials in

Four U.S. States

The Employment, Unemployment and

Unemployment Compensation Benefits of

Immigrants

The Returns to Education in Italy: A New Look at the Evidence

5

$3 / 00$

Are Immigrants Favorably Self-Selected? An

Economic Analysis

2

$2 / 00$

3

$2 / 00$

3

$2 / 00$

5

$2 / 00$

$2 / 00$

$2 / 00$

$3 / 00$

$3 / 00$

$3 / 00$

$3 / 00$

$3 / 00$

$3 / 00$

$3 / 00$

$1 / 3 \quad 3 / 00$

$13 / 00$


Empirical Analysis within the Augmented Solow Model

Wages, Hours and Human Capital over the

The Effects of Public Sector Sponsored Training on Individual Employment Performance in East Germany

142 J. J. Dolado F. Felgueroso

J. F. Jimeno

Explaining Youth Labor Market Problems in Spain: 3

Wage Determination in Russia: An Econometric Investigation

144 G. Saint-Paul

Flexibility vs. Rigidity: Does Spain have the worst of both Worlds?

Decomposition Analysis for a Binary Choice Model

Does the Recent Success of Some OECD Countries in Lowering their Unemployment Rates Lie in the Clever Design of their Labour Market Reforms?

148 L. Goerke

Employment Effects of Labour Taxation in an Efficiency Wage Model with Alternative Budget Constraints and Time Horizons 
J.-St. Pischke

151 M. Ward

152 J. J. Dolado

F. Felgueroso

J. F. Jimeno

153 A. S. Kalwij

M. Gregory

154 M. Gerfin

M. Lechner

155

J. Hansen

156
A. Björklund
T. Eriksson
M. Jäntti
O. Raaum
E. Österbacka

159 P.- J. Jost

M. Kräkel

160

M. Lofstrom

161
V. Gimpelson
D. Treisman
G. Monusova

162 C. Dustmann

M. E. Rochina-

Barrachina

163

R. A. Hart

Y. Ma

164 M. A. Shields

S. Wheatley Price

Z. MacDonald

M. A. Shields
Gender, Salary and Promotion in the Academic 5 Profession

The Role of the Minimum Wage in the Welfare 3

State: An Appraisal

Overtime Hours in Great Britain over the Period 3

1975-1999: A Panel Data Analysis

Microeconometric Evaluation of the Active Labour 6 Market Policy in Switzerland

The Duration of Immigrants' Unemployment Spells: $\quad 1 / 3$

Evidence from Sweden

Language Proficiency and Labour Market Per- 1

formance of Immigrants in the UK

Household Production, Full Consumption and $\quad 7$ the Costs of Children

Brother Correlations in Earnings in Denmark, 5 Finland, Norway and Sweden Compared to the United States

Preemptive Behavior in Sequential Tournaments

A Comparison of the Human Capital and Signaling Models: The Case of the Self-Employed and the Increase in the Schooling Premium in the 1980's

Public Employment and Redistributive Politics:

4

$6 / 00$

Evidence from Russia's Regions

Selection Correction in Panel Data Models: An 6 Application to Labour Supply and Wages

Why do Firms Pay an Overtime Premium?

5

$6 / 00$

Racial Harassment, Job Satisfaction and Intentions

5

$6 / 00$ to Quit: Evidence from the British Nursing Profession

Immigration in a High Unemployment Economy: 1 The Recent Danish Experience

The Impact of Alcohol Consumption on Occupa- 5 tional Attainment in England 
Wages and the Demand for Health - A Life Cycle

Timing, Togetherness and Time Windfalls

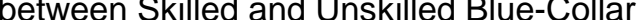
Workers within Establishments: An Empirical Analysis with Data of Manufacturing Firms

177 B. R. Chiswick

Immigrant Adjustment in Israel: Literacy and

Fluency in Hebrew and Earnings

178 R. Euwals M. Ward

The Renumeration of British Academics

180 T. K. Bauer I. N. Gang

Sibling Rivalry in Educational Attainment: in Perspective 